\title{
Strengthening of Reinforced Concrete beams: \\ RC versus UHPFRC layers
}

\author{
Andreas Lampropoulos, Ourania Tsioulou \\ University of Brighton, UK
}

\author{
Spyridon Paschalis
}

University of Bolton, UK

\author{
Stephanos Dritsos \\ University of Patras, Greece
}

Contact: a.lampropoulos@brighton.ac.uk

\begin{abstract}
Strengthening of Reinforced Concrete $(\mathrm{RC})$ beams is of high importance for the structural upgrade of existing buildings. The majority of the existing RC structures need to be upgraded either because they are designed with old or without seismic code provisions or because of existing damages. In this study the effectiveness of the use of traditional RC layers is compared with the use of Ultra High Performance Fibre Reinforced Concrete (UHPFRC) layers. Experimental investigation has been conducted on beams strengthened with these two techniques and the effectiveness of the examined methods has been evaluated via comparisons of the load-deflection and the interface slip results.
\end{abstract}

Keywords: strengthening, beams, reinforced concrete layers, UHPFRC.

\section{Introduction}

The structural upgrade of existing structures is a key priority worldwide and especially in earthquake prone areas. The selection of the most appropriate strengthening techniques and materials is case-dependent and is highly affected by the requirements of the examined structures.

Concrete reinforced with steel bars is traditionally used for the enhancement of the structural performance of deficient buildings [1]. Remarkable development has been achieved in the last decade in the use of novel high performance materials and especially Ultra High Performance Fibre Reinforced Concrete (UHPFRC) [2-5]. UHPFRC is a material with enhanced strength in tension and compression and significantly high energy absorption in the post crack region. A high percentage of steel fibres is used to increase the tensile strength and enhance ductility. UHPFRC's superior mechanical properties, particularly its high tensile strength and the durability, make it suitable for the protection of existing structures while it also allows the construction of relatively thin layers or jackets. 
The aim of this study is to provide an in-depth evaluation of the effectiveness of these two techniques. Reinforced Concrete (RC) beams strengthened with RC or UHPFRC layers have been examined. Full scale tests have been conducted and the effectiveness of the examined techniques for the improvement of the flexural performance of Reinforced Concrete (RC) beams has been evaluated using load-deflection results. In addition to this, the interface conditions and the contribution of the reinforcement of the additional layers have been examined. The enhancement of the flexural response of the strengthened beams has been critically evaluated in terms of stiffness and load capacity and the interface conditions have been examined using slip measurements at the interface.

\section{Experimental results of RC beams strengthened with additional layers}

In this section, experimental results of two main studies focused on the strengthening of beams with RC [1] and UHPFRC [2] layers are presented. The examined specimens in these two studies $[1,2]$ have quite similar geometry and loading setups which allow some direct comparisons and a critical evaluation of the effectiveness of the two methods.

\subsection{Beams strengthened with RC layers}

In this section, experimental results of the flexural strengthening of $\mathrm{RC}$ beams with additional $\mathrm{RC}$ layers will be presented [1].

The initial $\mathrm{RC}$ beam (Figure 1 ) had a rectangular cross section of $150 \mathrm{~mm}$ by $250 \mathrm{~mm}$ and a length of $2200 \mathrm{~mm}$. The initial beams were reinforced on their tensile side with $2 \Phi 12$ B500 steel with a cover of $25 \mathrm{~mm}$ (Figure 1a). Stirrups with a diameter of $8 \mathrm{~mm}$ and spacing of $100 \mathrm{~mm}$ and $50 \mathrm{~mm}$ were placed as shear reinforcement as illustrated in Figure 1. The compressive strength of the concrete of the initial beam was found to be equal to 39.5 $\mathrm{MPa}$. Strengthening was performed by adding a new concrete layer of $50 \mathrm{~mm}$ thickness reinforced with 2Ф12 B500 steel. Two strengthening beams were examined, one with roughened interface to a depth of 2 to $3 \mathrm{~mm}\left(\mathrm{~T}_{1}\right)$, one with less roughening of approximately 1 to $2 \mathrm{~mm}\left(\mathrm{~T}_{2}\right)$. The compressive strength of the concrete of the new layers was found to be $38.9 \mathrm{MPa}$ and $34 \mathrm{MPa}$ for specimens $\mathrm{T}_{1}$ and $T_{2}$ respectively.

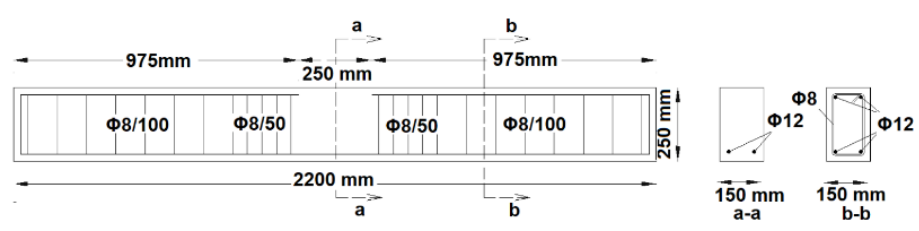

(a)
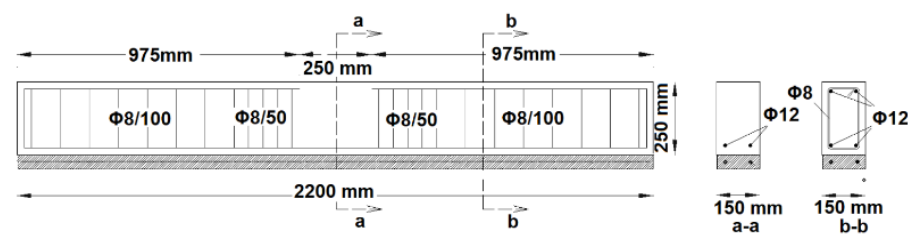

(b)

Figure 1. a) Initial and b) Strengthened beams with RC layers

The loading conditions are illustrated in Figure 2. The span length is $2000 \mathrm{~mm}$ and the distance between the loading points (s) applied to the middle of the element is $500 \mathrm{~mm}$.

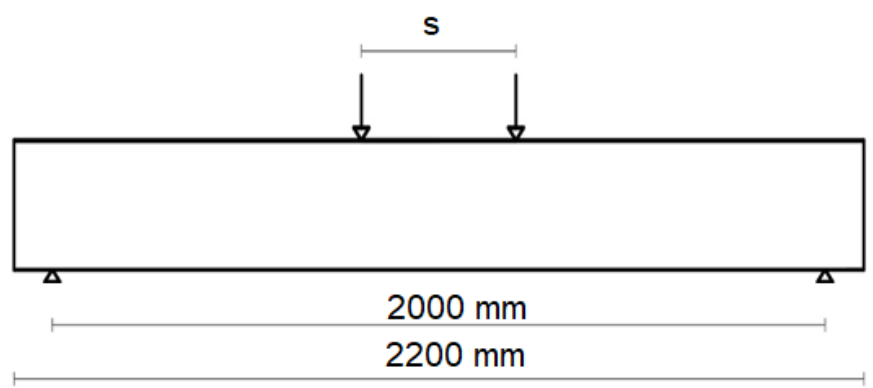

Figure 2. Loading conditions of the beams where the application of $R C$ layers is examined 
The load deflection results of the examined beams are presented in Figure 3.

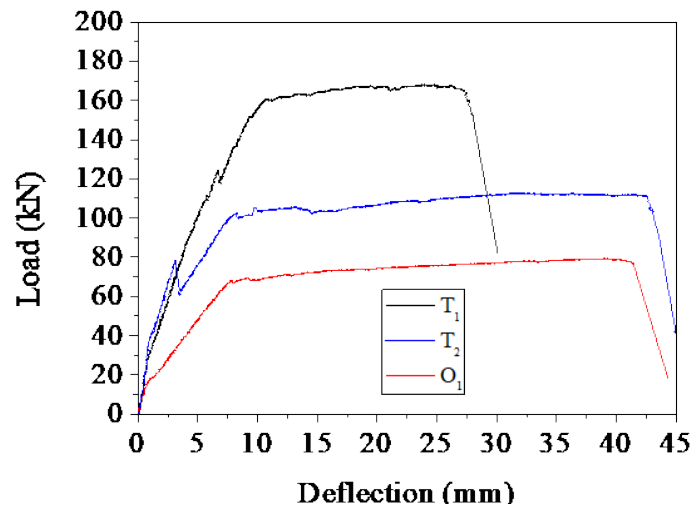

Figure 3. Load versus deflection results for beams strengthened with RC layers [1]

The results show that the stiffness of the $\mathrm{RC}$ beams has been significantly enhanced, as expected, and the maximum load capacity has also been improved in both specimens $T_{1}$ and $T_{2}$. However, specimen $T_{2}$ experienced premature failure due to the lower degree of roughness of the interface.

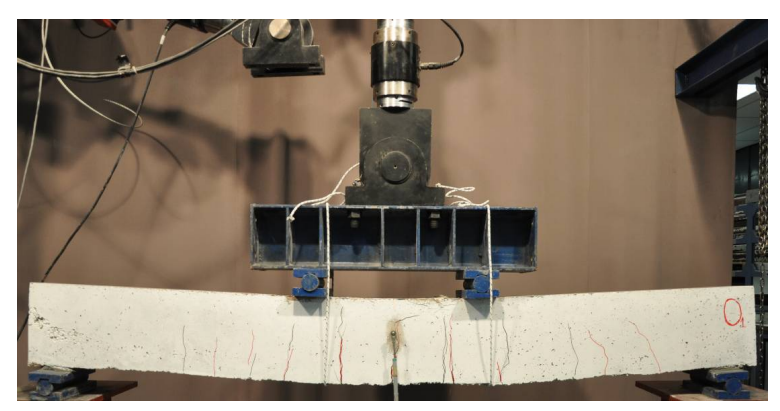

(a)

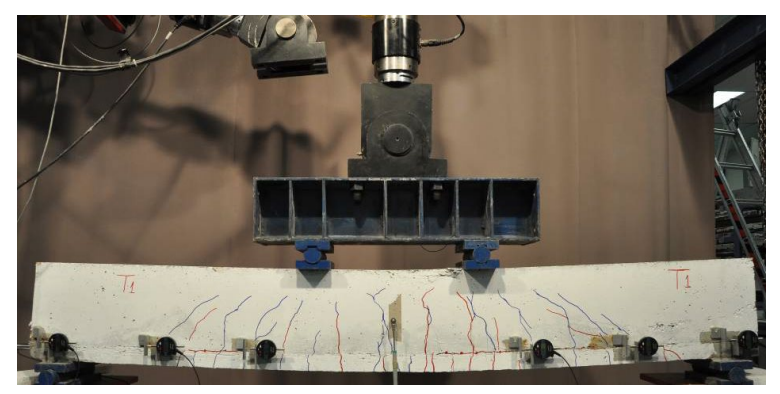

(b)

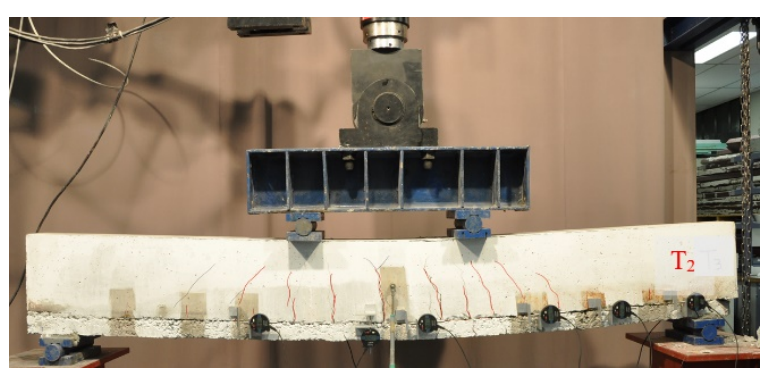

(c)

Figure 4. Failure mode for the maximum load capacity of specimens a) 01, b) $T 1$ and c) $T 2$

Figure 4, shows the failure mode of the examined specimens at a loading stage near the maximum load capacity of Figure 3 . From the failure modes of the three examined cases (Figure 4), it is evident that flexural cracks occurred mostly occurred in all the specimens while there are also some shear cracks which occurred after the formation of the main flexural cracks. Also, in specimen $T_{2}$, delamination of the new concrete layer occurred which is evident in Figure $4 c$ and reflects to the drop of the load capacity of this specimens which is presented in Figure 3.

The load and deflection values for the characteristics points of yield $\left(\mathrm{P}_{\mathrm{y}}, \delta_{\mathrm{y}}\right)$ and failure $\left(\mathrm{P}_{\mathrm{u}}\right.$, $\left.\delta_{u}\right)$ and the initial stiffness $(K)$ at $3 \mathrm{~mm}$ mid-span deflection have been obtained using the results of Figure 3 and the values are presented in Table 1.

Table 1. Experimental results for characteristic points

\begin{tabular}{cccc}
\hline & $\mathbf{T}_{\mathbf{1}}$ & $\mathbf{T}_{\mathbf{2}}$ & $\mathbf{O}_{\mathbf{1}}$ \\
\hline $\mathbf{P}_{\mathbf{y}}(\mathbf{k N})$ & 160 & 101 & 68 \\
$\boldsymbol{\delta}_{\mathbf{y}}(\mathbf{m m})$ & 10.5 & 8 & 8 \\
$\mathbf{P}_{\max }(\mathbf{k N})$ & 167 & 113 & 79 \\
$\boldsymbol{\delta}_{\mathbf{P a x}}(\mathbf{m m})$ & 26.5 & 42 & 39 \\
$\mathbf{K}(\mathbf{k N} / \mathbf{m m})$ & 23 & 26 & 11
\end{tabular}

The slip along the interface was measured experimentally using digital micrometres at the supports and then at incremental distances of 330 $\mathrm{mm}$ towards the middle of the beams as presented in Figure 4. The distribution of the slip values for 
specimens $\mathrm{T} 1$ and $\mathrm{T} 2$ are presented in Figures $5 \mathrm{a}$ and $5 b$.

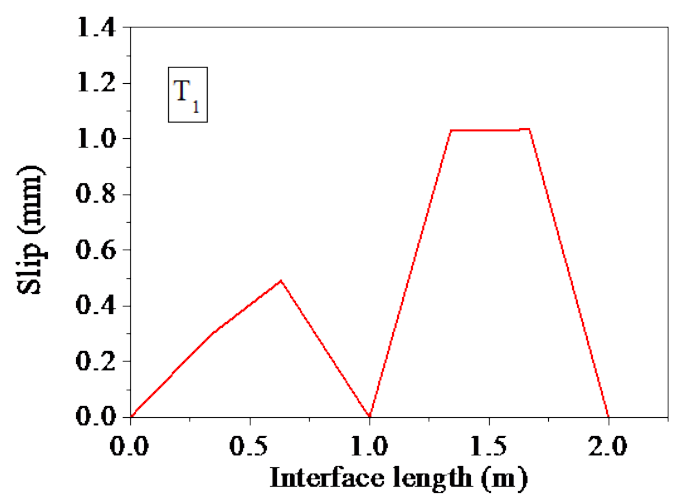

(a)

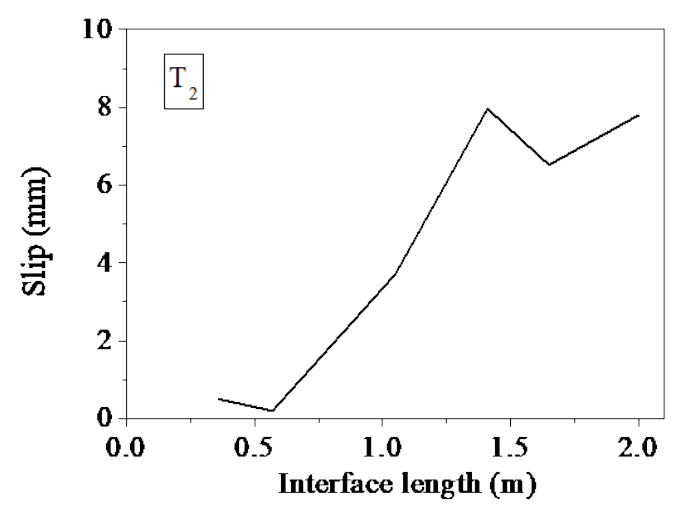

(b)

Figure 5. Slip distribution along the interface for the maximum load capacity for a) $T_{1}$ and b) $T_{2}$

The results of Figure 5 show that the degree of roughness plays a crucial role for the structural performance of the examined beams since slip values up to $1 \mathrm{~mm}$ were measured for the specimen $\mathrm{T}_{1}$ with the well roughened interface, while in case of $T_{2}$ with poor interface treatment, failure occurred with delamination of the layer and very high interface slip values of approximately $8 \mathrm{~mm}$ were measured.

The results of the elements strengthened with UHPFRC layers are presented in section 2.2.

\subsection{Beams strengthened with UHPFRC layers}

Beams with similar geometry and properties to the ones presented in section 2.1, were examined and strengthened using UHPFRC layers [2] (Figure 6). Two initial beams $(P)$ were reinforced with two longitudinal ribbed steel bars with a diameter of 12 $\mathrm{mm}$ and length of $2150 \mathrm{~mm}$ steel bars, at the tensile side in order to represent relatively weak beams. Stirrups with a diameter of $10 \mathrm{~mm}$ and spacing of $150 \mathrm{~mm}$ were placed as shear reinforcement.

For the strengthened specimens, UHPFRC layers with $50 \mathrm{~mm}$ thickness were cast along the whole length of the beams (Figure 6). Before the casting of the layers the surface of the initial beams was roughened to a depth of 2-2.5 $\mathrm{mm}$, similar degree of roughness with the one used for specimen $T_{1}$. Two specimens were examined without any additional steel bars in the layer $(U)$ while the addition of two ribbed steel bars with $10 \mathrm{~mm}$ diameter B500 steel was also examined in another two specimens $\left(U_{B}\right)$. Plastic spacers were used in order to ensure the required concrete cover of 25 $\mathrm{mm}$ in both the initial beam and the UHPFRC layers. The compressive strength of the concrete of the initial beam was found to be equal to $30.9 \mathrm{MPa}$. UHPFRC was found to have a compressive strength of $136.5 \mathrm{MPa}$ and a tensile strength of $11.5 \mathrm{MPa}$ at the day of the testing of the strengthened beams [2].

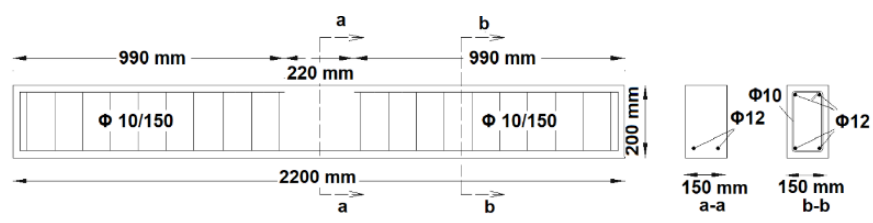

(a)

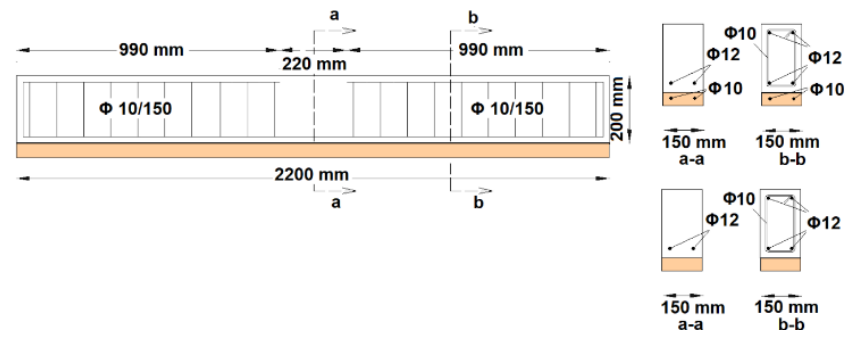

(b)

Figure 6. a) Initial and b) Strengthened beams with UHPFRC layers 
The loading setup is the same with the one presented in Figure 2 with spacing between the loading points (s) equal to $400 \mathrm{~mm}$. Two specimens were examined for each type of specimens, and the averages of the two specimens are presented in Figure 7.

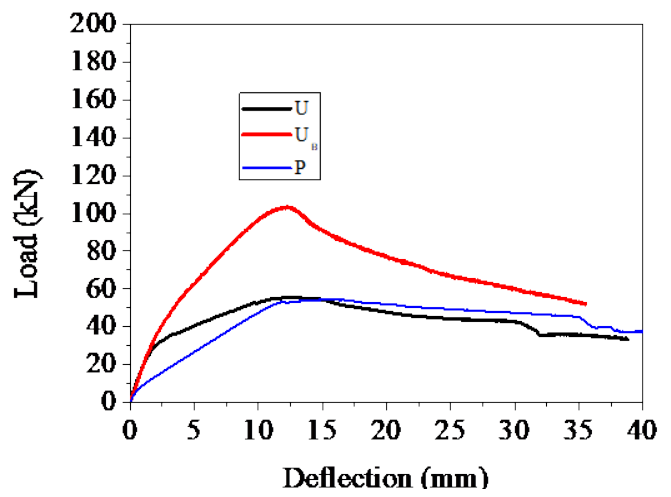

Figure 7. Load versus deflection results for beams strengthened with UHPFRC layers [2]

The results of Figure 7 show that the addition of an UHPFRC layer without steel bars (U) leads to an increment of the initial stiffness. However, the maximum load capacity and the post peak behaviour of these specimens (U) are quite similar to the response of the initial beams $(P)$ since the UHPFRC has failed at these loading stages. The behaviour is different for the specimen strengthened with the layer with steel bars $\left(U_{B}\right)$ where significant increment of the load capacity is achieved, in addition to the stiffness enhancement, due to the presence of the longitudinal steel bars.

The failure modes of the examined specimens at a loading stage near the maximum load capacity are presented in Figure 8.

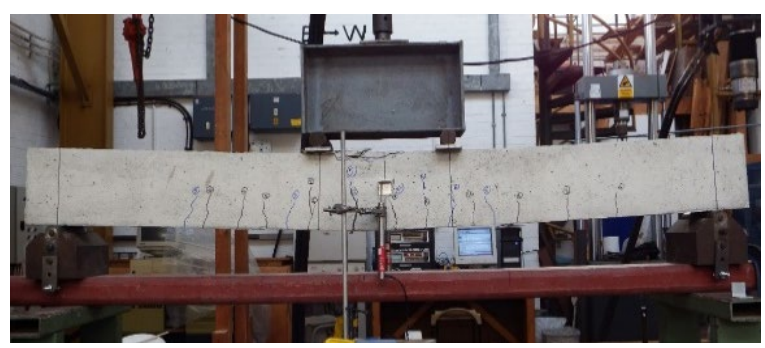

(a)

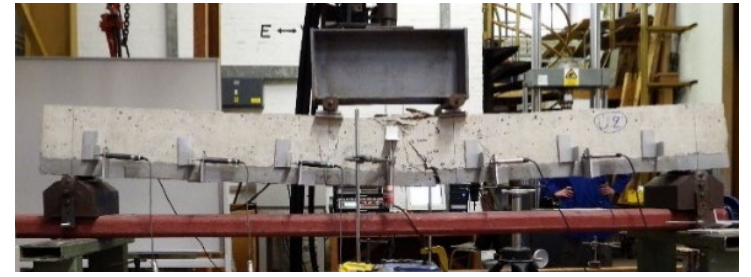

(b)

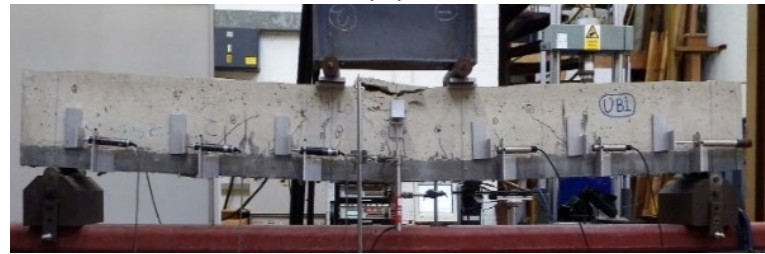

(c)

Figure 8. Failure mode for the maximum load capacity of specimens a) $P, b) \cup$ and c) $U_{B}$

The failure modes indicate flexural failure in all the examined specimens. Also, it is evident from Figure $8 \mathrm{~b}$ that a main crack is formed at the tensile side in the case of $U$ specimens where UHPFRC layer without steel bars has been used which reflects to the reduction of the load capacity and the change of the initial slope of the load-deflection curve after the initiation of crack.

The load and deflection values for the characteristic points of yield $\left(P_{y}, \delta_{y}\right)$ and failure $\left(P_{u}\right.$, $\left.\delta_{u}\right)$ and the initial stiffness $(K)$ at $3 \mathrm{~mm}$ mid-span deflection have been obtained

Table 2. Experimental results for characteristic points

\begin{tabular}{cccc}
\hline & $\mathbf{U}$ & $\mathbf{U}_{\mathrm{B}}$ & $\mathbf{P}$ \\
\hline $\mathbf{P}_{\max }(\mathbf{k N})$ & 55.34 & 103.49 & 54.55 \\
$\boldsymbol{\delta}_{\mathbf{P} \max }(\mathbf{m m})$ & 12.26 & 12.23 & 15.88 \\
$\mathbf{K}(\mathbf{k N} / \mathbf{m m})$ & 12 & 15 & 6
\end{tabular}

The slip along the interface was measured experimentally using Linear Variable Differential Transformers (LVDTs) starting at a distance 100 $\mathrm{mm}$ from the supports and at incremental distances of $300 \mathrm{~mm}$ towards the middle of the beams as presented in Figure 8 . Distribution of the slip values for specimens $U$ and $U_{B}$ are presented in Figure 9. 


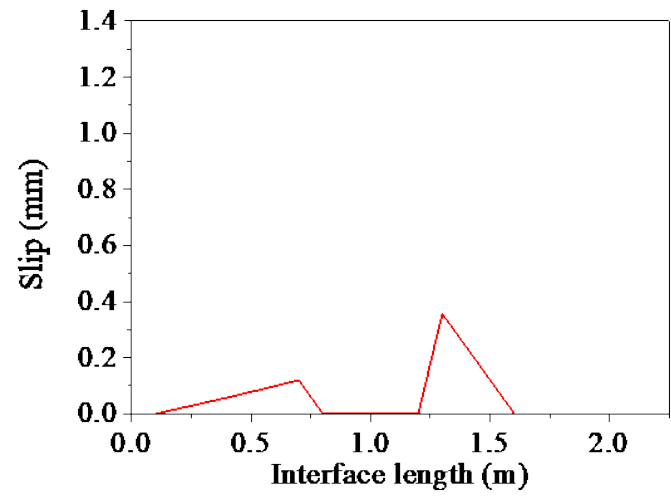

(a)

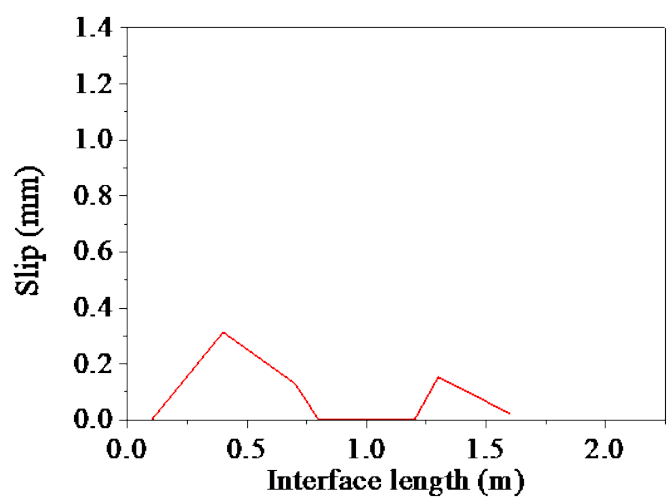

(b)

Figure 9. Slip distribution along the interface for the maximum load capacity for a) $U$ and b) $U_{B}$

The results of the slip distributions along the interface show maximum slip values below $0.4 \mathrm{~mm}$ in both $U$ and $U_{B}$ specimens which indicate very good connection between UHPFRC and the existing concrete substrate.

\section{$3 \quad \mathrm{RC}$ versus UHPFRC layers}

In this section, an evaluation of the effectiveness of the two examined techniques is presented. Comparisons are presented for the stiffness and the ultimate load capacity while the interface conditions are also examined using the results of the interface slip.
The stiffness increment, compared to the respective values of the initial beams, is presented in Figure 10.

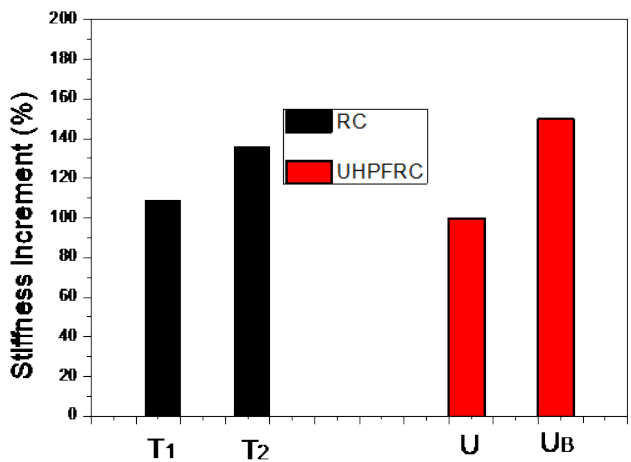

Figure 10. Stiffness increment results

From the results of Figure 10, it can be observed that in all the examined specimens the stiffness increment (at $3 \mathrm{~mm}$ mid-span deflection) was found to be in the range of $100-150 \%$. The highest stiffness increment (150\%) was found for specimen $U_{B}$ where UHPFRC layers reinforced with steel bars were used. The specimen with UHPFRC without any steel bars (U) show $100 \%$ increment of the stiffness while the respective results for the specimens strengthened with $\mathrm{RC}$ layers were found in the range $109-136 \%$.

The maximum load increment results are presented in Figure 11 . The maximum load increment results show that negligible increment of the ultimate load was achieved by the addition of UHPFRC layer without steel bars (U) due to the damage localisation and the formation of a major crack at the UHPFRC layer which led to significant reduction of the initial stiffness of the strengthened element (Figure 7). Therefore, the results of specimen $U$ are approaching the results of the initial beam $(P)$ for the maximum load and the post peak region of the load-deflection graph (Figure 7). The specimen with UHPFRC layers and steel bars $\left(U_{B}\right)$ show a significant ultimate load strength increment of $90 \%$. And in this case the failure occurred by concrete crushing at the compressive side of the examined specimen. The other two specimens with the conventional RC layers show an 
increment of $43 \%$ and $111 \%$ for the specimen with poor $\left(T_{2}\right)$ and well-roughened interfaces respectively $\left(T_{1}\right)$. It should be mentioned that the steel bars used in specimens $T_{1}$ and $T_{2}$ had $12 \mathrm{~mm}$ diameter while in case of specimen $U_{B}$ steel bars with $10 \mathrm{~mm}$ diameter were used. Therefore, in order to make a direct comparison of the maximum load capacity results, the maximum load of specimens $T_{1}$ and $T_{2}$ have been adjusted by multiplying the increment of the maximum load capacity with the ratio of the cross sectional area of $10 \mathrm{~mm}$ to $12 \mathrm{~mm}$ steel bars $\left(T_{1}\right.$ adj, $T_{2}$ adj $)$. The results of specimens $T_{1}$ adj and $T_{2}$ adj were found equal to $77 \%$ and $30 \%$ respectively, values lower than the $90 \%$ increment which was observed in specimen $U_{B}$ (Figure 11).

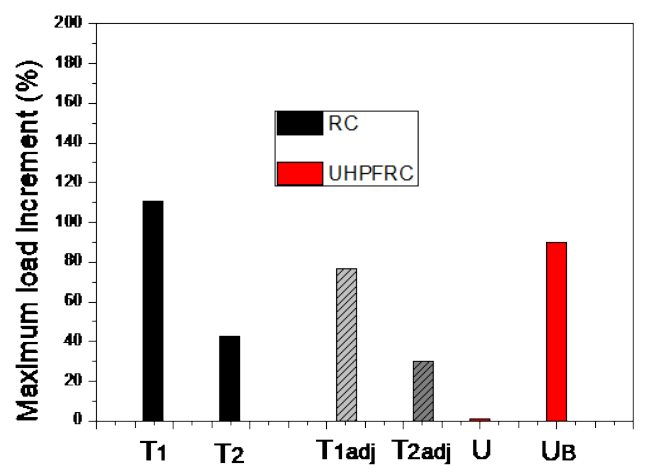

Figure 11. Maximum load increment results

The maximum interface slip along the interface for the maximum load capacity of all the examined specimens is presented in Figure 12.

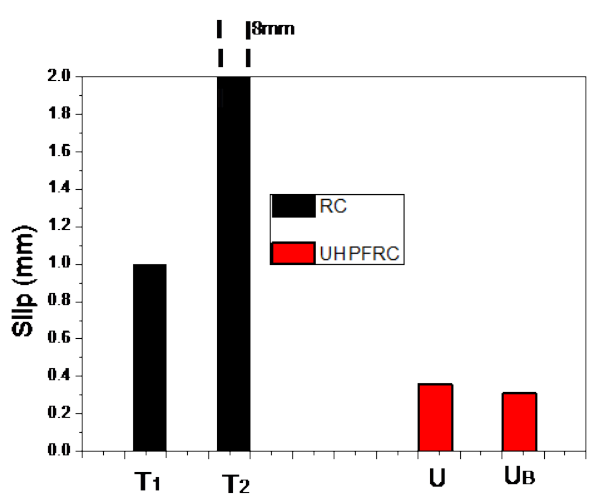

Figure 12. Maximum interface slip results
The results of Figure 12 show that in both specimens $U$ and $U_{B}$ the interface slip values are significantly lower compared to the $T_{1}$ and $T_{2}$ specimens which proves the enhanced interface connection of the UHPFRC layers compared to the traditional RC layers. More specifically, the maximum slip for the strengthened beams with RC layers was $1 \mathrm{~mm}$ and $8 \mathrm{~mm}$ for the specimens with well roughened $\left(T_{1}\right)$ and poor interface conditions $\left(T_{2}\right)$, while the values for the strengthened beams with UHPFRC layers were found equal to $0.36 \mathrm{~mm}$ and $0.31 \mathrm{~mm}$ for specimens $U$ and $U_{B}$. The enhanced interface conditions in case of specimens strengthened with UHPFRC layers was also visually observed from the failure modes (Figure 8) where absence of cracks during the loading was observed at the interfaces. In case of specimens strengthened with RC layers, cracks and slips at the interface were also visually observed from the failure mode of the examined beams (Figure 4).

\section{Conclusions}

This study is focused on the evaluation of the effectiveness of additional layers for the flexural strengthening of RC beams. Conventional concrete and UHPFRC were the two main materials used for the additional layers while the effect of the addition of steel bars reinforcement was also examined. Experimental work was conducted, and the main conclusions are drawn below:

- Strengthened specimens with UHPFRC layers show the lowest slip values and below $0.4 \mathrm{~mm}$ in both of the examined specimens, while the respective values for specimens strengthened with RC layers were found considerably higher and equal to $1 \mathrm{~mm}$ and $8 \mathrm{~mm}$ for well roughened and poor interface conditions respectively.

- The specimens which were strengthened with UHPFRC layers and steel bars were found to be the most efficient ones, with the maximum stiffness and load capacity increment and the lowest interface slip values.

- Strengthened beams with UHPFRC layers showed significant enhancement of the initial stiffness. In case of specimen with UHPFRC layer without steel bars, a major 
crack was formed at the UHPFRC layer which led to significant reduction of the initial stiffness of the strengthened element and subsequent reduction of the maximum load and post peak capacity which was approximately the same with the behaviour of the unreinforced beam.

- The addition of the RC layers leads to significant enhancement of stiffness and maximum load capacity provided that well roughened interface conditions are ensured.

- In case of strengthened beams with RC layers and poor interface conditions, premature failure occurred leading to reduced load capacity enhancement.

\section{References}

[1] Tsioulou O., Lampropoulos A. and Dritsos S. Experimental investigation of interface behaviour of RC beams strengthened with concrete layers. Construction and Building Materials. 2012; 40: 50 - 59, 2012.

[2] Paschalis S., Lampropoulos A. and Tsioulou $O$. Experimental and numerical study of the performance of ultra high performance fiber reinforced concrete for the flexural strengthening of full scale reinforced concrete members. Construction and Building Materials. 2018; 186: 351 - 366.

[3] Lampropoulos A., Paschalis S., Tsioulou 0. and Dritsos S. Strengthening of reinforced concrete beams using ultra high performance fibers reinforced concrete(UHPFRC). Engineering Structures. 2015; 106: $370-384$.

[4] Bastien Masse M., Brühwiler E. Contribution of R-UHPFRC Strengthening layers to the shear resistance of RC elements. Structural Engineering International. 2016; 4, 365-374.

[5] Al-Majidi M.H., Lampropoulos A., Cundy A., Tsioulou O., and Alrekabi S. Flexural performance of reinforced concrete beams strengthened with fibre reinforced geopolymer concrete under accelerated corrosion. Structures. 2019; 19: 394-410. 